\title{
COGNITIVE INTERVENTION WITH ELITE PERFORMERS: REVERSAL THEORY
}

\author{
J. H. KERR, BEd, MA, Associate Professor
}

Department of Physical Education, Netherlands School of Business

\begin{abstract}
Noticeable in the literature associated with the application of psychology to the area of sport and sports performance in particular has been the increasing frequency of references to the use of cognitive intervention in the sports context. Currently utilised in clinical psychology and behavioural medicine, and receiving increasing attention in sports psychology, are a number of intervention techniques primarily oriented towards altering the individual's level of arousal. These techniques, which have been advocated for use by sports performers as an aid to adapting and coping during competition, have been largely concerned with arousal reduction. This paper presents an alternative approach, the case of reversal theory, a new general theory of psychology concerned with motivation, and emphasises the conceptual implications of this new approach for the use of cognitive intervention techniques in sport.
\end{abstract}

Key words: Reversal theory, High arousal, Cognitive intervention, Relaxation, Anxiety

\section{INTRODUCTION}

Beginning a paper with a cautionary note may be unusual, nevertheless, in this case it seems warranted. It should be pointed out that some of the papers found in the growing literature on proposals for cognitive interventions in sport are positively biased, especially in the claims made with respect to improving sports performance. Some of the reports make claims that in reality cannot be justified and the concerns of some other authors in this respect should not be ignored. As Mahoney (1984), writing about cognitive interventions, points out,

"... it is imperative that a cognitive skills advocate remain both cautious and accountable in making assertions about what an athlete or coach 'should' do to improve performance. Thus, the remarks which follow and those that appear in subsequent sections should be viewed as intervention possibilities rather than direct or confident recommendations. They hardly exhaust the list of possible cognitive skills strategies that might assist athletic performance, and it goes without saying that they are in need of controlled experimental evaluation." (p. 14-15)

Along similar lines, Heyman (1984) states,

“... cognitive interventions are derived from clinical approaches. They are more than just 'techniques'. They were developed as part of therapeutic approaches to psychological and behavioural change. It is not always easy to determine when a sport participant's problems are only related to sport or are more comprehensive, and when the application of a cognitive intervention to the sport problem may be inappropriate." (p. 269).

Whilst the use of cognitive interventions in sport provides a new and exciting challenge for those involved in sports psychology, the different concerns of Mahoney and

\footnotetext{
Address for correspondence:

John H. Kerr, BEd, MA

Associate Professor

Department of Physical Education

Nijenrode

Netherlands School of Business

Straatweg 25

3621 BG Breukelen

Netherlands
}

Heyman, reflected above, should be kept in mind. Indeed, it is worth noting that some psychologists working in other areas of psychology have yet to be convinced of the value of cognitive interventions (see Wolpe 1976 a \& b, and Skinner 1977).

Although sports competitors and coaches have for a long time considered that arousal levels may be an important factor with respect to sports performance, empirical evidence is both contradictory and confusing. This situation has led to rather broad and largely unhelpful generalisations being made about which level of arousal is appropriate for particular sports events, e.g. Oxendine (1984), Landers and Boutcher (1986). The only clear conclusions arising out of research reports and theoretical papers are that individual variations, particularly in mental state, and the nature of the sports events are crucial elements in the arousal-performance relationship.

An example of a rather less generalised approach to the psychological preparation of top level performers is provided by the work of Rushall (e.g. 1982). He has attempted to formulate detailed strategies and competitionspecific plans aimed at the enhancement of competitive performance. These strategies and plans are based on research and the results of evaluations of the behaviour of sports performers, the nature of specific sports situations and the characteristics of the sports and their participants. The mental state of the athlete or performer is considered especially crucial and Rushall is one of those who advocates the use of "on-site" intervention techniques should it be necessary. This would occur when the mental state of the performer was thought to be inappropriate for the demands of the particular competition environment. Whilst the competition-specific focus of the work is praiseworthy, its "behaviourist" foundation may mean that the confidence with which his ideas are advocated may not be shared by other researchers.

One particularly enduring notion is that of over-arousal, the idea that the individual performer's level of arousal becomes so high that it interferes negatively with performance. As a result of this, sports psychologists have turned to techniques utilised in arousal control and specifically arousal reduction in an attempt to assist sports competitors to improve the consistency of and increase their performance. These intervention techniques were already being used in clinical psychology and behavioural medicine to help patients relax. Progressive relaxation and autogenic training, along with systematic desensitisation, 
are well-established. The idea of relaxation incorporated in these techniques is used synonymously with the idea of arousal reduction. Biofeedback and transcendental meditation are almost always used with relaxation and the lowering of the individual's level of arousal in mind.

This lowering of arousal, however, need not always be an appropriate strategy to use. There are some authors (e.g. Mahoney, 1984 and Railo, 1982) who are recognising the importance of some sports performers achieving high levels of arousal prior to and during competition. Several recent research studies (e.g. Caudill, et al, 1983) have indicated that increasing subjects' arousal levels or "psyching up" facilitated performance. Stallings states:

"The fact that arousal is, to a large extent, qualitatively specific to the individual may appear to the practitioner to be an insurmountable barrier to the selection of arousal-producing techniques. However, since many of the methods discussed in the section on reducing arousal are designed to increase the individual's awareness of physiological states (e.g. degree of muscle tension), their possible use to teach an individual to increase arousal should be considered." (Stallings, 1982)

In addition, elite athletes interviewed by Garfield and Bennett (1984) reported a number of characteristic sensations associated with top performance. These reported sensations included feelings of "joy", "ecstasy" and "intensity" and the feeling of being "highly energised".

Reversal theory (Apter, 1982) postulates that the motivation of many people for participating in sport is found in the pleasant experience of high arousal which is intrinsic to many sports activities (see Kerr, 1985).

Before attempting to describe the alternatives that reversal theory proposes for cognitive intervention, it is only sensible that a short description of reversal theory be included to assist in understanding the concepts involved. However, this description is by no means exhaustive; readers are referred to Apter's 1982 text for a comprehensive description.

\section{THE THEORY OF PSYCHOLOGICAL REVERSALS: A DESCRIPTION}

The theory of psychological reversals is a phenomenological theory of motivation and, consequently, the importance of the individual and the individual's experience is a central feature of its conceptual stance. It is, however, rather different to other phenomenological theories because it attempts to examine human action in a systematic manner and provide a structure to the way in which individuals experience their own motivation. Put succinctly, "structural phenomenology focusses on the different ways in which the contents of experience are interpreted by the individual, rather than on the contents themselves." (Apter, 1982, p. 16).

This individual interpretation means that cognitive and emotional factors play an important role in reversal theory, as does the underlying principle that the behaviour of any individual is inconsistent when considered over time. In other words, there will often be occasions when an individual's behaviour is not consistent with the way they behave in general.

From what has been said so far, it may seem, given the theory's position on the inconsistency of behaviour and its attempt to provide a structure to the individual's experience of motivation, that forming a conceptual basis for reversal theory is extremely difficult, if not impossible. This might well be the position, except that a number of novel concepts have been proposed by reversal theory which enables it to tackle these difficulties.

The first of these reversal theory concepts has its origins in cybernetics and comes from a development in cybernetics concerned with the understanding of action by means of system models. One specific class of "multistable" systems is characterised by having a variety of alternative preferred or stable states. The bistable system is one type of multistable system and, as its name suggests, has two alternative preferred stable states between which the system finds itself operating at any one time. It is the notion of bistability which has been incorporated into reversal theory to overcome the limitations of the homeostatic system construct currently prevalent in psychology. The homeostatic notion argues that organisms have only one preferred stable state, a fundamental element in a number of other theoretical approaches, for example, optimal arousal theory. However, serious questions have been raised about the usefulness of the homeostatic system approach (e.g. Harlow, 1953; Allport, 1960 and Frankl, 1969).

A very simple example of a bistable system is a light switch which can be either "on" or "off", either of which are stable positions, but any position in between these two is unstable. Bistability in reversal theory means that for an individual, the particular conditions pertaining at the time, such as aspects of the environment or biological functioning, are thought to govern which of the two states is preferred.

The idea of bistability is tied in with two other concepts referred to within the theory as "metamotivational states" and "reversals". Metamotivational states are phenomenological states characterised by the manner in which an individual interprets some aspect(s) of his or her motivation. Four sets of metamotivational states have been identified and have been linked together as opposing pairs (telic-paratelic, negativism-conformity, autocentric-allocentric, sympathy-mastery). The reason they are linked together as paired opposites may become more obvious if we examine what psychologists usually mean by the word "state" and consider a practical example of how reversal theory encapsulates the notion of metamotivational states. Murgatroyd (1985) points out that,

“The term 'state' in psychology is used to describe something about a person at a given moment in time. States can change quickly, can last for varying durations of time (from seconds to days) and can be affected by environmental cues, interpersonal transections, cognitive processes, biological changes and motivation." (p. 4)

From this description it is apparent that a state is a somewhat temporary situation and that in time this position will change. This is precisely what is thought to occur between pairs of metamotivational states in reversal theory, with the change which takes place between them known as a "reversal". Take for example the telic-paratelic pair, which is especially relevant to the topic of the motivation and mental states of elite sports performers. In the telic state, the individual is usually serious-minded, planning oriented and has a preference for low arousal. Conversely, an individual would tend to be spontaneous, playful and present-oriented, preferring high arousal and the pleasure 
of immediate sensation whilst in the paratelic state (see Table 1 below).

TABLE I

Contrasting characteristics of the telic and paratelic states (from Apter, 1982 p. 52)

\begin{tabular}{|c|c|c|}
\hline & Telic & Paratelic \\
\hline $\begin{array}{l}\text { Mean-Ends } \\
\text { Dimension }\end{array}$ & $\begin{array}{l}\text { Essential goals } \\
\text { Imposed goals } \\
\text { Unavoidable goals } \\
\text { Reactive } \\
\text { Goal-oriented } \\
\text { End-oriented } \\
\text { Attempts to complete } \\
\text { activities }\end{array}$ & $\begin{array}{l}\text { No essential goals } \\
\text { Freely chosen goals } \\
\text { Avoidable goals } \\
\text { Proactive } \\
\text { Behaviour oriented } \\
\text { Process-oriented } \\
\text { Attempts to prolong activity }\end{array}$ \\
\hline $\begin{array}{l}\text { Time } \\
\text { Dimension }\end{array}$ & $\begin{array}{l}\text { Future-oriented } \\
\text { 'Points beyond itself' } \\
\text { Planned } \\
\text { Pleasure of goal } \\
\quad \text { anticipation } \\
\text { High significance } \\
\text { preferred }\end{array}$ & $\begin{array}{l}\text { Present-oriented } \\
\text { 'Sufficient unto itself' } \\
\text { Spontaneous } \\
\text { Pleasure of immediate } \\
\text { sensation } \\
\text { Low significance } \\
\text { preferred }\end{array}$ \\
\hline $\begin{array}{l}\text { Intensity } \\
\text { Dimension }\end{array}$ & $\begin{array}{l}\text { Low intensity preferred } \\
\text { Synergies avoided } \\
\text { Generally realistic } \\
\text { Low arousal preferred }\end{array}$ & $\begin{array}{l}\text { High intensity preferred } \\
\text { Synergies sought } \\
\text { Make-believe prevalent } \\
\text { High arousal preferred }\end{array}$ \\
\hline
\end{tabular}

The special relationship that exists between the experience of felt arousal and hedonic tone when in the telic or paratelic states is shown graphically in Fig. 1.

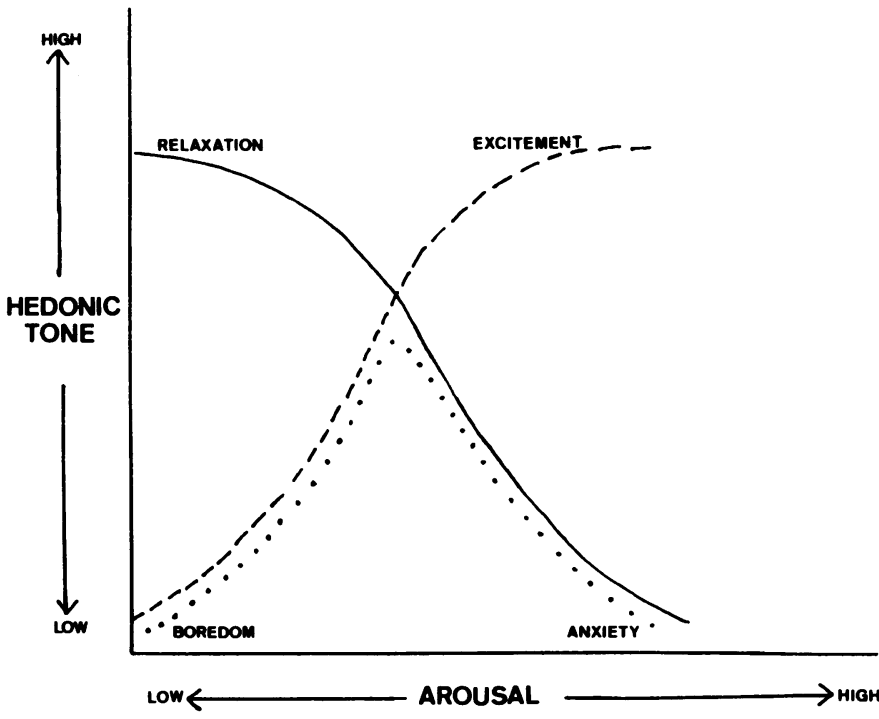

Fig. 1: The relationship between arousal and hedonic tone for the telic state (solid line) and the paratelic state (broken line). The dotted line indicates the single curve of optimal arousal theory (from Apter, 1982).

The four words "excitement", "anxiety", "boredom" and "relaxation", common in everyday speech, capture the feelings associated with high or low felt arousal in the telic and paratelic states.

Apter (1982) uses the example of swimming to illustrate an activity that is often undertaken in the paratelic state,

"As one swims, one experiences the feeling of surging movement, of water streaming over one's skin and the impression of temporary escape from gravity and freedom to move in any direction. All these may be intense experiences of exactly the kind which are relished in the paratelic state." (p. 59)

Nevertheless, it is dangerous to associate any particular behaviour with any specific mental state. Here, for example, the activity of swimming for the elite swimmer, working towards and competing in high level competition is likely to take on a telic orientation. The concern then is with training schedules, "split-times" and "personal bests".

Incidentally, individuals are thought to have a preference for either of the two metamotivational states and are said to be either telic or paratelic "dominant". This represents an individual bias in the experience of metamotivational states and a scale has been developed to measure this tendency, known as the Telic Dominance Scale (see Murgatroyd, 1985). A person categorised as telic dominant is considered to spend more time in the telic state than in the paratelic state. It should be noted that "dominance" is a rather different notion to that of "trait" common in other personality measures. The idea of a personality trait suggests that the individual's behaviour tends to be consistent and that there is a predisposition to act in a particular way. For example, when an individual is classified as "extrovert" this indicates that extroverted behaviour is a regular and stable characteristic of that individual's personality. The difference is subtle, but important in reversal theory because of its phenomenological base and view of human behaviour as fundamentally inconsistent. In brief, the suggestion from reversal theory is that a person could react in one of two ways, in this instance either telic or paratelic, depending on his/her metamotivational state at the time, with the possibility of switching or reversing between them. So that "the term 'dominant' reflects the ascendency of one state over another... for a particular person rather than that person's desire to be telic or paratelic: it is the description of what the person actually tends to experience over time rather than a statement about how he or she might wish to be." (Murgatroyd, 1985, p. 20)

By incorporating the innovative concepts outlined above into the reversal theory approach, a unique interpretation of human action becomes viable. The phenomenological framework underpinning reversal theory allows a number of alternative cognitive intervention possibilities to be considered.

\section{POSSIBILITIES FOR THE USE OF COGNITIVE INTERVENTION TECHNIQUES WITH ELITE SPORTS PERFORMERS}

Where cognitive intervention techniques have been used in clinical psychology the emphasis has been on arousal reduction. Treatment involving the reduction of arousal levels has proved effective with some patients who have problems controlling anxiety, however, the use of this type of intervention technique may not be effective in all cases. Recent research undertaken by Heide and Borkovec (1983) and Budzinski, et al (1980) has shown that some subjects are unable to achieve a state of low arousal and for others relaxation training can paradoxically induce anxiety.

The general concern amongst sports psychologists is that athletes should be able to control arousal levels in order to find a so-called optimal level of arousal which they consider will be of most benefit in enhancing performance. Here again, the emphasis has been on using arousalreducing techniques and currently not much attention is being given to other possibilities. Reversal theory, however, suggests that arousal reduction is not the only intervention 
possibility and that there are three other equally effective methods open to the therapist (see Svebak and Stoyva, 1980; Kerr, in press).

These alternative strategies, which could be used to change or cause a reinterpretation of arousal levels are outlined in Fig. 2 below.
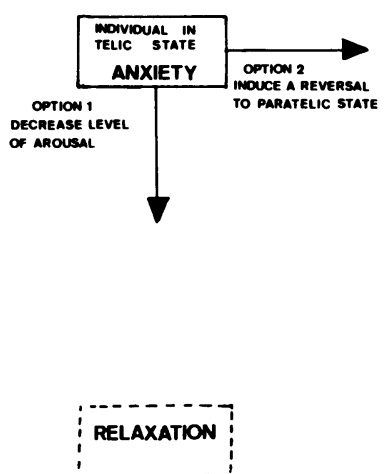
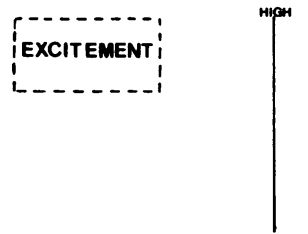

FELT AROUSAL

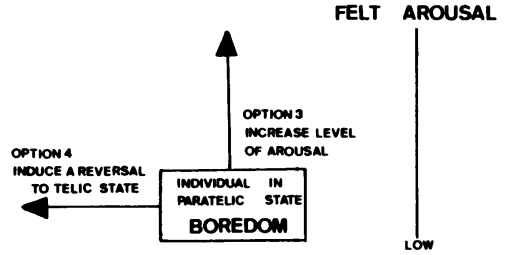

Fig. 2: Possible options for affecting felt arousal (from Kerr in press).

Reversal theory proposes four possible strategies. These are:-

\section{A. High Arousal:}

(1) Reducing the level of high arousal, experienced as unpleasant, by utilising one of the techniques described above, for example progressive relaxation.

(2) Causing a reinterpretation of unpleasant high arousal by bringing about a metamotivational reversal (i.e. telic to paratelic).

\section{B. Low Arousal:}

(3) Increasing the level of low arousal, experienced as unpleasant by, for example, utilising an innovative biofeedback technique.

(4) Causing a reinterpretation of unpleasant low arousal by bringing about a metamotivational reversal (i.e. paratelic to telic).

Although for the individual in the telic state arousal reduction would be appropriate, resulting in unpleasant feelings of anxiety being changed to pleasant feelings of relaxation, it would be inappropriate for the individual in the paratelic state. Here low levels of arousal are experienced as unpleasant boredom, so what is required is an increase in arousal level which would then be experienced by the individual as excitement. How might this be achieved? One possibility is the suggestion made by Svebak and Stoyva (1980) that biofeedback, one of the self-regulatory techniques, could be used. Subjects would learn to voluntarily increase arousal rather than the opposite.

By effecting metamotivational reversals, two other possibilities for the use of intervention present themselves. These would result in a reinterpretation of arousal, as perceived by the individual, thus changing the hedonic tone. A reversal from paratelic to telic would allow unpleasant feelings of boredom to be reinterpreted as relaxation. On the other hand, high arousal in the telic state, experienced as unpleasant, could be changed to feelings of excitement following a reversal to the paratelic state.

It is imperative, especially prior to or, depending on the event, during competitive performance, to be able to recognise when inappropriate metamotivational states are operative. A "state" type self-report scale, the Telic
Dominance Scale, state version, has been constructed which could be used for this purpose. Sports psychologists, or perhaps coaches who know their team or individual competitors well, could be taught to recognise when an inappropriate metamotivational state is operative. It also seems likely that the sports performers themselves could through experience learn to identify when their operative mental state was not consistent with their usual precompetitive metamotivational state. It would then be necessary to bring about a reversal.

Reversal theory proponents consider that once the need for a reversal has been pinpointed, an individual, in this case the elite sports performer, could bring about an environmental change in such a way to trigger a reversal. In addition, it is thought that elite performers could induce a reversal by means of a cognitive restructuring or imaging strategy. A recent publication by Murgatroyd and Apter (in press) examines methods for inducing reversals and their usefulness as a means of psychotherapeutic intervention.

\section{CONCLUDING REMARKS}

In putting forward the case of reversal theory and its implications for the use of cognitive interventions in sport, the words of caution made at the beginning of the paper are still relevant. Not only is the use of cognitive interventions in sport in its infancy, but so too is reversal theory. In terms of its growth, the first major publication came out in 1982. There is still a considerable amount of work to be undertaken. The empirical and other research investigations carried out. to date have been supportive. Reversal theory, like the application of cognitive intervention to the context of sport, holds a great deal of promise, therefore it is important that those people involved with enhancing the performance of elite sports competitors performing at the highest level should be made aware of the possibilities opened up by this new approach.

\section{ACKNOWLEDGEMENTS}

An earlier version of this paper was presented at the XXIII FIMS World Congress of Sports Medicine held in Brisbane, Australia 20-28 September, 1986.

\section{References}

Allport, G. W., 1960. Personality and Social Encounter. Boston: Beacon Press. Apter, M. J., 1982. The Experience of Motivation: The Theory of Psychological Reversals. London: Academic Press.

Budzinski, T. H., Stovva, J. M. and Peffer, K. E., 1980 "Biofeedback techniques in psychosomatic disorders". In: Handbook of Behavioral Interventions. A Clinical Guide. A. Goldstein and E. Foa. New York: Wiley.

Caudill, D., Weinberg, R. and Jackson, A., 1983 "Psyching up and track athletes: a preliminary investigation". Journal of Sport Psychology 5: 231-235.

Frankl, V. E., 1969. The Will to Meaning: Foundations and Applications of Logotherapy. New York: Plume.

Garfield, C. A. and Bennett, H. Z., 1984. Peak Performance: Mental Training Techniques of the World's Greatest Athletes. Los Angeles: Tarcher.

Harlow, H. F., 1953 "Motivation as a factor in the acquisition of new responses". In: Current Theory and Research in Motivation: A Symposium. M. R. Jones. Lincoln, Nebraska: University of Nebraska Press.

Heide, F. J. and Borkovec, T. D., 1983 "Relaxation and induced anxiety paradoxical anxiety enhancement due to relaxation training". Journal of Consulting and Clinical Psychology 51: 171-182.

Heyman, S. R., 1984 "Cognitive interventions: theories, applications and cautions". In: Cognitive Sport Psychology. W. F. Straub and J. M. Williams. New York: Sport Science Associates.

Kerr, J. H., 1985 "A new perspective for sports psychology". In: Reversal Theory: Applications and Developments. M. J. Apter, D. Fontana and S. Murgatroyd. Cardiff, Wales: University College Cardiff Press. 
Kerr. J. H., in press. "Anxiety, arousal and sport: An application of reversal theory". In: Anxiety in Sports: an International Perspective. Series in Health Psychology and Behavioral Medicine. D. Hackfort and C. D. Spielberger. Hemisphere Publishing.

Landers, D. M. and Boutcher, S. H., 1986 "Arousal-performance relationships". In: Applied Sport Psychology. J. M. Williams. Palo Alto, California: Mayfield Publishing Company.

Mahoney, M. J., 1984 "Cognitive skills and athletic performance". In: Cognitive Sport Psychology. W. F. Straub and J. M. Williams. Lansing, New York: Sports Science Associates.

Murgatroyd, S., 1985 "The nature of telic dominance". In: Reversal Theory: Applications and Developments. M. J. Apter, D. Fontana and S. Murgatroyd. Cardiff, Wales: University College Cardiff Press.

Murgatroyd, S. and Apter, M. J., in press. "A structural phenomenological approach to eclectic psychotherapy". In: Handbook of Eclectic Psychotherapy. J. Norcross. New York: Bruner/Mazel.

Oxendine, J. B., 1984. Psychology of Motor Learning. Englewood Cliffs, New Jersey: Prentice-Hall.

Railo, W. S., 1982 "Psychological self-training of superior athletes". In: Mental Training for Coaches and Athletes. T. Orlick, J. Partington and J. H. Salmela. Ottawa, Canada: Sport in Perspective Inc. and Coaching Association of Canada.

Rushall, B. S., 1982 "On-site psychological preparation for athletes". In: Mental Training for Coaches and Athletes. T. Orlick, J. Partington and J. H. Salmela. Ottawa, Canada: Sport in Perspective Inc. and Coaching Association of Canada.

Skinner, B. F., 1977 "Why I am not a cognitive psychologist". Behaviorism 5: 1-10.

Stallings, L. M., 1982. Motor Learning from Theory to Practice. St. Louis, Missouri: C. V. Mosby Company.

Svebak, S. and Stowva, J., 1980 "High arousal can be pleasant and exciting. The theory of psychological reversals". Biofeedback and Self-Regulation 5 (4): $439-444$.

Wolpe, J., 1976a "Behavior therapy and its malcontents - I. Denial of its basis and psychodynamic fusionism". Journal of Behavior Therapy and Experimental Psychiatry 7: 1-5.

Wolpe, J., 1976b "Behavior therapy and its malcontents - II. Multimodal eclecticism and 'exposure' empiricism". Journal of Behavior Therapy and Experimental Psychiatry 7: 109-116.

\section{GLOSSARY OF TERMS FROM REVERSAL THEORY}

ALLOCENTRIC STATE. A metamotivational state in which pleasure and displeasure derive primarily from what happens to someone else rather than what happens to oneself at the time in question. It forms a pair with the autocentric state.

AROUSAL (FELT). The degree to which an individual feels himself to be 'worked up' at a given time, and in this sense the degree of intensity of his feelings of motivation. The felt arousal dimension defined in this way is different from the sleep-wakefulness dimension.

AUTOCENTRIC STATE. A metamotivational state in which pleasure and displeasure derive primarily from what happens to oneself rather than what happens to someone else at the time in question. It forms a pair with the allocentric state.
BISTABILITY. A system exhibits bistability if it tends to maintain a specified variable, despite external disturbance, within one or another of two ranges of values of the variable concerned.

CONFORMIST STATE. A metamotivational state in which the individual wants, or feels compelled to comply with, some requirement. It forms a pair with the negativistic state.

DOMINANCE. A metamotivational state is said to be dominant, or 'state-dominant', if the individual is predisposed to spend longer periods in this state than in the other member of the pair which they together constitute. It is measured by the Telic Dominance Scale.

MASTERY STATE. A metamotivational state in which the individual seeks to master the other with whom he is interacting at the time. It forms a pair with the sympathy state.

METAMOTIVATIONAL STATE. Phenomenological state characterised by a certain way of interpreting some aspect(s) of one's own motivation. Metamotivational states go in pairs of opposites, only one member of each pair being operative at a given time.

NEGATIVISTIC STATE. A metamotivational state in which the individual wants, or feels compelled to act against, some requirement. It forms a pair with the conformist state.

PARATELIC STATE. Metamotivational state in which the individual is oriented towards some aspect of his continuing behaviour and related sensations. Forms a pair with the telic state. Characteristics - activity for its own sake, playfulness, spontaneity, preference for high intensity experience and low felt significance.

REVERSAL. A reversal is a switch from one operative metamotivational state to the other member of the pair.

SYMPATHY STATE. A metamotivational state in which the individual seeks to be liked by the other with whom he is interacting at the time. In this state, transactions with the other are seen as involving giving or being given. It forms a pair with the mastery state.

STRUCTURAL PHENOMENOLOGY. The study of the structure of experience, and the way in which the nature of this structure changes over time. That is, it primarily concerns the structure of experience itself, rather than particular structures which occur within experience.

TELIC STATE. (Greek 'telos', goal or end). Metamotivational state in which the individual is oriented towards some essential goal(s). Characteristics - serious-mindedness, planning ahead, preference for low intensity experiences and high felt significance. 